Open Access

\title{
Prevalence and predictors of Pap smear cervical epithelial cell abnormality among HIV-positive and negative women attending gynecological examination in cervical cancer screening center at Debre Markos referral hospital, East Gojjam, Northwest Ethiopia
}

Melkamu Getinet ${ }^{1}$, Baye Gelaw², Abinet Sisay ${ }^{1}$, Eiman A. Mahmoud ${ }^{3}$ and Abate Assefa ${ }^{2 *}$

\begin{abstract}
Background: Cervical cancer is the leading cause of cancer related death among women in developing countries. Cervical cancer is preceded by cervical surface epithelial cell abnormalities (ECA) which can be detected by Pap smear test. Simultaneous human papillomavirus and human immunodeficiency virus (HIV) infection increases cervical cancer. Data on the prevalence and predictors of ECA among women in Ethiopia is limited. Hence, we aimed to determine the prevalence and associated factors of ECA among women.

Methods: A comparative cross-sectional study was conducted among HIV+ and HIV-women attending gynecological examination in cervical cancer screening center at the Debre Markos referral hospital. The study subjects were stratified by HIV status and systematic random sampling method was used to recruit study participants. Cervical smears were collected for Pap smear examination. Logistic regression analysis was employed to examine the possible risk factors of cervical ECA.

Results: A total of $197 \mathrm{HIV}+$ and $194 \mathrm{HIV}$ - women were enrolled in the study. The overall prevalence of cervical ECA was $14.1 \%$ of which the prevalence of atypical squamous cells undetermined significance (ASCUS), low grade squamous intraepithelial lesion (SIL), high grade SIL, squamous cell carcinoma and ASC, cannot exclude high grade SIL (ASCH) were 5.1, 3.8, 4.1 and 1.0 \%, $0.0 \%$ respectively. Significantly higher prevalence of ECA (17.8\%) was observed among HIV+ women (COR 1.9, $95 \% \mathrm{Cl}: 1.1-3.4, p=0.036)$ as compared to HIV-women (10.3 \%). Multiple sexual partnership (AOR 3.2, $95 \% \mathrm{Cl}: 1.1-10.0, p=0.04$ ), early ages of first sexual contact ( $<15$ years) (AOR 5.2, $95 \% \mathrm{Cl}: 1.5-17.9, p=0.009$ ), parity greater than three (AOR 10.9, $95 \% \mathrm{Cl}: 4.2-16.8, p<0.001$ ) and long term oral contraceptive pills (OCP) use (AOR 11.9, $95 \% \mathrm{Cl}: 2.1-16.7, p=0.02$ ) were significant predictors of prevalence of ECA.

Conclusions: Cervical ECA is a major problem among HIV-infected women. Lower CD4+ T-cell counts of below 350 cells/ $\mu$ l, HIV infection, multiple sexual partnership, early age at first sexual contact, parity greater than three and long term OCP use were significant predictors of prevalence of ECA. Strengthening screening program in HIV+ women should be considered.
\end{abstract}

\footnotetext{
* Correspondence: abezew@gmail.com

${ }^{2}$ Department of Medical Microbiology, School of Biomedical and Laboratory

Sciences, College of Medicine and Health Sciences, University of Gondar,

Gondar, Ethiopia

Full list of author information is available at the end of the article
}

C Biomed Central

(c) 2015 Getinet et al. Open Access This article is distributed under the terms of the Creative Commons Attribution 4.0 International License (http://creativecommons.org/licenses/by/4.0/), which permits unrestricted use, distribution, and reproduction in any medium, provided you give appropriate credit to the original author(s) and the source, provide a link to the Creative Commons license, and indicate if changes were made. The Creative Commons Public Domain Dedication waiver (http://creativecommons.org/publicdomain/zero/1.0/) applies to the data made available in this article, unless otherwise stated. 


\section{Background}

Squamous intraepithelial lesions (SIL) are an abnormal growth of squamous epithelial cells of the ecto-cervix. Cervical epithelial cell abnormalities (ECA) represent a spectrum of SIL that lie along the pathway, from mildto-severe dysplasia to invasive cancer [1]. Cervical carcinoma develops gradually through well characterized precursor lesions [2]. Greater than $99.7 \%$ cervical cancer is attributed by human papillomavirus (HPV) infection. HPV usually causes a variety of benign papillomatous lesions of the skin and mucosal basal epithelium $[3,4]$. There are more than 100 different HPV genotypes [5]. Based on oncogenic potential, HPV is classified as high-risk (HR) and low-risk (LR) oncogenic types. HRHPV types, HPV 16, 18, 31, 33, 35, 39, 45, 51, 52, 56, 58, 59, 68 and 82, cause anogenital cancer [6], while infection with LR-HPV types, HPV 6 and 11, is associated with benign genital warts. HR-HPV types are detected in $99 \%$ of cervical cancer, and about $70 \%$ of cervical cancer is due to HPV 16 and 18 [7].

More than half of sexually active people become infected with HPV during their lifetime [8]. It is estimated that in Ethiopia about $33.6 \%$ of women in the general population has HPV infection [9]. Persistent infection with HR-HPV types over time leads to the development and progression of cervical intraepithelial neoplasia (CIN). Not all women who acquire HPV infection do develop CIN. Rather approximately $90 \%$ of HPV infections clear within 2 years [10]. The peak of HPV infection in women occurs in the late teens and early twenties following sexual exposure $[11,12]$. Cervical cancer associated with HPV infection also leads to infertility. There is higher incidence of ECA among women complaining of infertility [13].

Cervical ECA can be detected and classified by cytological screening methods. Well organized programmes of regular gynecological screening and treatment of precancerous lesions have been very effective in preventing cervical cancer [14, 15]. Cytological examination of cervical scrapping from clinically suspicious cases by Papanicolaou (Pap) cytological screening test can detect cervical ECA. The Pap smear identifies any changes in cells of the transformation zone of the cervix [16]. The Bethesda System 2001 classifies ECA into atypical squamous cell (ASC), low-grade squamous intraepithelial lesion (LSIL), high-grade squamous intraepithelial lesion (HSIL) and squamous cell carcinoma (SCC). ASC comprises: ASC of undetermined significance (ASCUS) and ASC, cannot exclude HSIL (ASCH); LSIL encompasses: HPV, mild dysplasia, and CIN1; while HSIL includes: moderate and severe dysplasia, carcinoma in situ, CIN 2, and CIN 3. These categories promote specificity in the mode of treatment [17]. For patients with invasive lesions the stage of a cervical cancer is the most important factor in the selection of treatment modality. For women diagnosed with ASCUS and LSIL follow up with HPVDNA testing, Pap smear or colposcopy within certain time interval is some of the management options. In general, noninvasive SIL identified using Pap smear only, are treated with superficial ablative procedures such as cryotherapy or laser therapy [18].

On a global level, $75 \%$ of women has abnormal cervical cytology at least once in their life time which may progress to cervical cancer. Cervical cancer is the second most common women cancer worldwide of which $80 \%$ occurs in developing countries. The higher prevalence of cervical ECA due to HPV was reported in African countries [19-21]. Current estimates indicates that in Ethiopia 4648 women are diagnosed annually with cervical cancer and 3235 die from the disease [9]. Several factors such as number of sexual partners and age of first sexual activity, smoking, immune-suppression, and presence of other sexually transmitted infection (STI) can increase the risk of developing cervical cancer [22]. Several studies revealed that human immunodeficiency virus (HIV) infection is associated with an increased risk of HPV related cervical ECA [23-25]. Mortality and morbidity due to cervical cancer is higher among HIV patients [26-28]. HIV infection and cervical cancer among women in Ethiopia are major public health problems. More than 534,000 adult women are estimated to be infected with HIV and at risk of developing cervical cancer. However, Ethiopia has invested little in the infrastructure, training, and laboratory capacity required for successful cytological screening [29]. Though studies have shown that the prevalence of ECA is more common among HIV-infected than non HIV-infected women, such data in Ethiopia is limited. For the development of a rational approach to the screening and the subsequent management of precancerous cervical lesion in HIV-infected women, understanding of the specific risk factors associated with ECA occurrence among HIV-positive women is very much important. The aim of this comparative study was to determine the prevalence of ECA and risk factors associated with its occurrence among HIV+ and HIVwomen attending the Debre Markos referral hospital.

\section{Methods}

\section{Study setting and design}

A comparative cross-sectional study was conducted among HIV- and HIV + women attending at the Debre Markos referral hospital cervical cancer screening center from the $1^{\text {st of }}$ March to the $30^{\text {th }}$ of May, 2014. Debre Markos referral hospital is located in Debre Markos town in East Gojjam Zone $300 \mathrm{~km}$ North of Addis Ababa. According to July 2014 zonal statistical agency report, the town has an estimated population of 100,000. The hospital has cervical cancer screening and treatment 
center. The screening service is provided for all HIV+ women. All women attending the Debre Markos referral hospital during the study period for any gynecological problem were eligible for the study. Pregnant women, lactating women and women on menstrual cycle were excluded from the study. The sample size was determined using two population proportion formula with the assumption of $95 \%$ confidence interval (CI), $5 \%$ marginal error and $33.6 \%$ prevalence of ECA among HIV-infected women (15) and $10 \%$ nonresponse rate. Since there is no previous study done in Ethiopia among HIVwomen, the prevalence of ECA was assumed to be $50 \%$. Using this assumptions the final sample size becomes 400 (200 HIV+ and $200 \mathrm{HIV}$ - women). During the study period there were a total of 1600 HIV- and $2000 \mathrm{HIV+}$ women attending gynecological examination in cervical cancer screening center. The study subjects from both groups were selected by systematic random sampling method.

\section{Socio-demographic and clinical information}

Data was collected after obtaining written informed consent from each participant. A pre-tested structured questionnaire was used to collect socio-demographic and clinical information needed for the study. Sociodemographic and clinical information included in this study were age, marital status, age at first sexual intercourse, number of sexual partners, duration of oral contraceptive pills (OCP) use, condom use, alcohol use, smoking, prostitution, history of STI, CD4 + T-cell count and parity.

\section{Cytopathological examination}

The cervical smear specimens were collected by gynecologist. Cervical smears were taken with a wooden applicator stick, smeared on a microscopic slide, fixed immediately with $95 \%$ ethanol and allowed to air dry. The smears were stained with Pap stain, examined and graded according to the criteria of Bethesda classification system [17]. To ensure the quality of Pap smear results, 20 randomly selected patients were evaluated by gynecologist with colposcopic examination and visual inspection. Moreover, representative smears were reexamined by pathologists at the University of Gondar hospital blinded from the first results. In this regard 30 randomly selected positive and negative slides were blindly rechecked by a pathologist.

\section{HIV test and CD4+ T cell count}

HIV counseling and testing based the national guideline was offered to participants unaware of their HIV status. Whole blood sample of $8 \mathrm{ml}$ was collected from each study subject for HIV testing and CD4+ T-cell counts. HIV testing was done based on current national rapid HIV testing algorithms. For all HIV+ women, CD4+ T-cell counts were determined by Fluorescent Activated Cell Sorter (FACS) count (Becton Dickinson) at Debre Markos referral hospital.

\section{Statistical analysis}

Data was initially registered in a registration book and transferred to excel Microsoft spread sheet. Data was cleaned and checked for completeness before analysis using SPSS version 20 computer software. Descriptive statistical analysis was used to determine the sociodemographic and clinical characteristics of study participants and prevalence of cervical ECA. The prevalence of ECA was stratified by study subjects' HIV status. Associations of patient characteristics with ECA were assessed using a series of bivariate logistic regression analysis. Then, to control simultaneously for the possible confounding effects of the different variables; a multivariable model was fitted with stepwise variable selection among variables having $\mathrm{p}$-value $\leq 0.2$ at bivariate analysis. In both bivariate and multivariate analyses, the associations were expressed in odds ratios (OR) and $95 \%$ CI. For all cases p-value $<0.05$ were considered statistically significant.

\section{Ethical approval}

The study was reviewed and approved by ethical review committee of School of Biomedical and Laboratory Sciences, College of Medicine and Health sciences, University of Gondar and official permission was obtained from Debre Markos referral hospital higher management. A written informed consent was obtained from each study participant. All Pap smear positive results were referred to the department of obstetrics and gynecology for immediate treatment. The patients record were made anonymous and any identifying information were removed prior to analysis. Individual records were coded and accessed only by research staff members.

\section{Results}

Consistency of microscopy and colposcopic examinations Pap smear microscopic examination was undertaken initially by trained laboratory technologist. Results obtained were compared with results obtained by a pathologist and gynecologist for consistency. In this regard, ten positive Pap smeared slides were given to three of the readers and examined blindly. There was no discrepancy between the results of the laboratory technologist and the pathologist or the gynecologist results except for one sample that was diagnosed as LSIL by the laboratory technologist but as ASCUS by the pathologist (Table 1). 
Table 1 Consistency of the results of the 3 readers

\begin{tabular}{|c|c|c|c|c|c|c|c|c|c|}
\hline \multirow[t]{2}{*}{ Sample No } & \multicolumn{3}{|l|}{ Reader A } & \multicolumn{3}{|l|}{ Reader B } & \multicolumn{3}{|l|}{ Reader C } \\
\hline & Method & Result & Grade & Method & Result & Grade & Method & Result & Grade \\
\hline 20 & Msy & ECA & 1 & Msy & ECA & 1 & Cpy & ECA & - \\
\hline 55 & Msy & ECA & 2 & Msy & ECA & 2 & Cpy & ECA & - \\
\hline 90 & Msy & ECA & 3 & Msy & ECA & 3 & Cpy & ECA & - \\
\hline 111 & Msy & ECA & 1 & Msy & ECA & 1 & Cpy & ECA & - \\
\hline 146 & Msy & ECA & 2 & Msy & ECA & 2 & Cpy & ECA & - \\
\hline 244 & Msy & ECA & 2 & Msy & ECA & 1 & Cpy & ECA & - \\
\hline 281 & Msy & ECA & 1 & Msy & ECA & 1 & Cpy & ECA & - \\
\hline 307 & Msy & ECA & 1 & Msy & ECA & 1 & Cpy & ECA & - \\
\hline 331 & Msy & ECA & 3 & Msy & ECA & 3 & Cpy & ECA & - \\
\hline 343 & Msy & ECA & 1 & Msy & ECA & 1 & Cpy & ECA & - \\
\hline
\end{tabular}

Reader A trained data collector, Reader B pathologist, Reader C Gynecologist, Msy Microscopy, Cpy Colposcopy, ECA Epithelial cell abnormality, Grade 1 atypical squamous cell undetermined significance, Grade 2 Low grade squamous intraepithelial lesion, Grade 3 High grade squamous intraepithelial lesion, Grade 4 squamous cell carcinoma

\section{Socio-demographic data and clinical characteristics of the patients}

A total of 400 women (200 HIV+ and $200 \mathrm{HIV}$ - women) were enrolled in the study, but 9 patients ( $3 \mathrm{HIV}+$ and 6 HIV-) were excluded because the smears were not adequate for evaluation. Therefore, further analyses were restricted to 391 study subjects. The mean age of the study subjects was 35.02 years with standard deviation of \pm 8.41 years. Two hundred and thirty $(58.8 \%)$ of the women were married, and only 65 (16.6\%) were employed. Majority of the study participants (59.1\%) were urban dwellers. Hundred and seventy six (45.0\%) of the women had no formal education (Table 2).

The number of life time sexual partners, greater than two, was higher in HIV+ women $(66.6 \%)$ as compared to HIV- ones (33.6\%). First sexual contact at early age ( $<18$ years) was also higher among $\mathrm{HIV}+$ women $(56.0 \%)$ than HIV- women (44.0\%). About $26.1 \%$ of the study subjects had a history of STI. Two hundred and sixty seven participants (68\%) were accustomed to alcohol intake and $0.8 \%$ was currently smoking. About $5.4 \%$ of women used OCP for greater than 5 years and only $14.8 \%$ of the women used condom. The number of parity greater than two was lower in $\mathrm{HIV}+$ women compared to that of HIV- women (Table 3).

\section{Clinical examination and Pap smear results}

Clinical investigation was also conducted for all study subjects and $16.4 \%(64 / 391)$ were found to have abnormal clinical findings. Among patients who had abnormal clinical results, $60.9 \%$ (39/64) were positive for HIV. Abnormal vaginal discharge and contact bleeding were the most common clinical findings. In 56 (14.3\%) of the women abnormal vaginal discharge was observed, whereas $8(2.0 \%)$ of the women had contact bleeding. Pap smear examination revealed that
$55(14.1 \%)$ patients were positive for cervical ECA. Higher prevalence of ECA (17.8\%) was observed in $\mathrm{HIV}+$ women, of which the prevalence of ASCUS was $5.6 \%(\mathrm{n}=11), 0.0 \%$ ASCH, $6.1 \% \operatorname{LSIL}(\mathrm{n}=12)$, $5.1 \%$ HSIL $(n=10)$ and $1.0 \% \operatorname{SCC}(n=2)$. On the other hand, a $10.3 \%$ cervical ECA prevalence was found among $\mathrm{HIV}$ - women with a prevalence of $4.6 \%(n=9), 0(0.0 \%), 1.5 \%(n=3), 3.1 \%(n=6)$ and $1.0 \%(\mathrm{n}=2)$ for ASCUS, ASCH, LSIL, HSIL and SCC respectively (Table 4 ).

The prevalence of cervical ECA was high (51.9 \%) among HIV+ women with CD4 + T-cell count $<200$ cells $/ \mu \mathrm{l}$. The prevalence of ECA among women with CD4 + T-cell counts of 200-349 cells/ $\mu$ l and 350-500 cells/ $\mu$ l were $18.5 \%(\mathrm{n}=10)$ and $12.7 \% \quad(\mathrm{n}=7)$, respectively. On the other hand, relatively low prevalence $(6.6 \%)$ of ECA was found among women with CD4 + T-cell count greater than 500/ $\mu$ l (Fig. 1).

Risk factor analysis for cervical epithelial cell abnormality Both bivariate and multivariate logistic regression analyses were employed to determine factors associated with ECA. All variables tested in the bivariate logistic regression analysis were entered into multivariate analyses if they have $p$-value of $\leq 0.2$. The highest prevalence of cervical ECA (25.0 \%) was observed in older age women ( $>45$ years of old). Moreover, bivariate analysis showed that the prevalence of ECA was significantly higher among patients within the age groups of 30-45 years old and above (crude odds ratio (COR) 2.5, $95 \%$ CI: $1.2-5.1, p=0.012$; COR 4.2, 95 \% CI: $1.7-10.5, p=0.002$ respectively) as compared to younger women. Residence, educational status, condom use, smoking and alcohol consumption were not associated with the development of ECA. 
Table 2 Socio-demographic characteristics of women attending cervical cancer screening center at Debre Markos referral hospital

\begin{tabular}{|c|c|c|c|c|}
\hline \multirow[t]{2}{*}{ Characteristics } & \multicolumn{2}{|l|}{ HIV status } & \multicolumn{2}{|c|}{ Total n \% } \\
\hline & Positive n (\%) & Negative $\mathrm{n}(\%)$ & & \\
\hline \multicolumn{5}{|l|}{ Age( in year) } \\
\hline$<30$ & $73(49.0)$ & $76(51)$ & 149 & 38.1 \\
\hline $30-45$ & $102(51.5)$ & $96(48.5)$ & 198 & 50.6 \\
\hline$>45$ & $22(50.0)$ & $22(50.0)$ & 44 & 11.3 \\
\hline \multicolumn{5}{|l|}{ Marital status } \\
\hline Married & $92(40.0)$ & $138(60.0)$ & 230 & 58.8 \\
\hline Single & $10(32.3)$ & $21(67.7)$ & 31 & 7.9 \\
\hline Divorced & $49(69.0)$ & $22(31.0)$ & 71 & 18.2 \\
\hline Widowed & $46(78.0)$ & $13(22.0)$ & 59 & 15.1 \\
\hline \multicolumn{5}{|l|}{ Marital status } \\
\hline Orthodox & 185(52.4) & $168(47.6)$ & 353 & 90.3 \\
\hline Muslim & $5(31.2)$ & $11(68.8)$ & 16 & 4.1 \\
\hline Protestant & $7(31.8)$ & $15(68.2)$ & 22 & 5.6 \\
\hline \multicolumn{5}{|l|}{ Residence } \\
\hline Rural & $70(43.8)$ & $90(56.2)$ & 160 & 40.9 \\
\hline Urban & $127(55.0)$ & $104(45.0)$ & 231 & 59.1 \\
\hline \multicolumn{5}{|l|}{ Educational status } \\
\hline Illiterate & $96(54.5)$ & $81(45.5)$ & 176 & 45.0 \\
\hline Primary school & $59(58.4)$ & $41(40.6)$ & 101 & 25.8 \\
\hline Secondary\& above & $42(37.2)$ & $71(62.8)$ & 113 & 28.9 \\
\hline \multicolumn{5}{|l|}{ Occupation } \\
\hline Employed & $24(36.9)$ & $41(63.1)$ & 65 & 16.6 \\
\hline House wife/Farmer & $81(41.9)$ & $112(58.1)$ & 193 & 49.4 \\
\hline No work & $32(68.1)$ & 15(31.9) & 47 & 12.0 \\
\hline Daily laborer & 20(90.9) & $2(9.1)$ & 22 & 5.6 \\
\hline Commercial sex worker & $8(50.0)$ & $8(50.0)$ & 16 & 4.1 \\
\hline Others & $32(66.7)$ & 16(33.3) & 48 & 12.3 \\
\hline
\end{tabular}

HIV Human immunodeficiency virus

The higher proportion of cervical ECA (63.6\%) was accounted by HIV+ women. Even though HIV infection was not found as an independent risk factor for ECA in multivariate analysis, in the bivariate analysis it was significantly associated with developing ECA (COR 1.9, $95 \%$ CI:1.1-3.4, $P=0.036$ ). A downward trend of the prevalence of ECA along the increment of CD4+ T-cell counts was observed among HIV+ women. Significantly higher prevalence of ECA were observed in HIV+ women with CD4+ T-cell counts $<200$ cells/ $\mu$ l (adjusted OR (AOR) 14.1, $95 \%$ CI: $6.7-16.4, p<0.001)$ and between 200 and 349 cells/ $\mu \mathrm{l}$ all (AOR 9.6, $95 \%$ CI: $1.8-11.5, p=0.008$ ) as compared to patients with CD4+ T-cell counts of above $500 \mathrm{cells} / \mu \mathrm{l}$.
Women with a previous history of multiple lifetime sexual partners (more than two), were at high risk for developing ECA when compared to their counterparts with one or two sexual partner (AOR 3.2, $95 \% \mathrm{CI}$ : $1.0-10, p=0.048)$. Early age at first sexual contact $(<15$ years $)$ was also identified as a significant risk factor for the development of ECA (AOR 5.2, $95 \%$ CI: $1.5-17.9, p=0.009$ ). Association of marital status for the development of ECA was analyzed. Widowed (AOR3.2, $95 \% \mathrm{CI}: 1.2-8.8, p=0.021$ ) and divorced (AOR 3.0; $95 \%$ CI: $1.1-8.1 ; p=0.029$ ) women were at higher risk than women who are married. Women with high parity (parity greater than four) were ten folds more likely to develop ECA (AOR10.9, $95 \% \mathrm{CI}$; $4.2-16.8, p<0.001)$ than women with parity lower than three. OCP users for more than five years were found to be at higher risk of developing ECA (AOR11.9, 95 \% CI: $2.1-16.7, p=0.02$ ) (Table 5).

\section{Discussion}

The study showed that microscopic examination of Pap smear results by a trained laboratory technologist are comparable with the microscopic examination results of the same preparation observed by a pathologist. The current accepted practice is for the Pap smear to be examined by pathologist, while nurse responsibility is collection of the sample of cervical cells, and the technician responsibility is to prepare the slides with the pathologist responsible for slide readings and final reporting of findings. The comparable accuracy of the trained technologist reports of the Pap smear to the pathologist reports may indicate the possible utilization of trained technicians in the interpretations of Pap smears at the peripheral health facility where there is no pathologist.

In this study, $16.4 \%$ of the women had abnormal clinical findings. The most prevalent clinical finding (13.4 \%) was abnormal vaginal discharge but only $2.0 \%$ of the women had contact bleeding. Vaginal discharge is often a normal and regular occurrence. There are, however, types of discharge that may suggest underlying infectious etiology. Such abnormal discharge was considered when the vaginal discharge was yellow or green in color, chunky in consistency, and have a foul odor. Most abnormal discharges in the study were caused by yeast or bacterial infection. The prevalence of abnormal gynecological findings such as abnormal vaginal discharge and contact bleeding of the current study was relatively lower than abnormal clinical findings reported from India which was $20 \%$ and $6.7 \%$ respectively [30].

In this study, the overall prevalence of cervical ECA based on Pap smear test was $14.1 \%$ in which the prevalence of ASCUS, ASCH, LSIL, HSIL and SCC were 5.1, $0.0,3.8,4.1$ and $1.0 \%$ respectively. The prevalence of ECA among HIV+ women was $17.8 \%$ which is quite 
Table 3 Behavioral and clinical characteristics of women attending cervical cancer screening unit at Debre Markos referral hospital

\begin{tabular}{|c|c|c|c|c|c|}
\hline Variable & & \multicolumn{2}{|l|}{ HIV status } & \multicolumn{2}{|c|}{ Total } \\
\hline \multirow[t]{2}{*}{ No. of life time sexual partner } & $1-2$ & $106(41.7)$ & 148(58.3) & 254 & 65.0 \\
\hline & $>2$ & $91(66.4)$ & $46(33.6)$ & 137 & 35.0 \\
\hline \multirow[t]{3}{*}{ Age of $1^{\text {st }}$ sexual contact } & $<18$ & $160(56.0)$ & 126(44.0) & 286 & 73.1 \\
\hline & $18-20$ & 25(32.0) & $53(68.0)$ & 78 & 19.9 \\
\hline & $>20$ & $12(44.4)$ & 15(55.6) & 27 & 6.9 \\
\hline \multirow[t]{2}{*}{ Alcohol use } & Yes & $142(53.2)$ & 125(46.8) & 267 & 68.3 \\
\hline & No & $55(44.4)$ & $69(55.6)$ & 124 & 31.7 \\
\hline \multirow[t]{2}{*}{ Smoking } & Yes & $2(66.7)$ & $1(33.3)$ & 3 & 0.8 \\
\hline & No & 195(50.3) & 193(49.7) & 388 & 99.2 \\
\hline \multirow[t]{2}{*}{ History of STI } & Yes & $66(64.7)$ & $36(35.3)$ & 102 & 26.1 \\
\hline & No & $131(45.3)$ & 158(54.7) & 289 & 73.9 \\
\hline \multirow[t]{2}{*}{ Duration of OCP usage } & $<5$ years & 43(55.8) & $34(44.2)$ & 77 & 19.7 \\
\hline & $>5$ years & 13(61.9) & $8(38.1)$ & 21 & 5.4 \\
\hline \multirow[t]{3}{*}{ Condom use } & Always & $40(69.0)$ & 18(31.0) & 58 & 14.8 \\
\hline & Some times & $52(46.8)$ & $59(53.2)$ & 111 & 28.4 \\
\hline & Never & 105(47.3) & $117(52.7)$ & 222 & 56.8 \\
\hline \multirow[t]{3}{*}{ Parity } & $\leq 2$ & 122(52.6)) & $110(47.4)$ & 232 & 59.3 \\
\hline & $3-4$ & 39(49.4) & $40(50.6)$ & 79 & 20.2 \\
\hline & $>4$ & $36(45.0)$ & $44(55.0)$ & 80 & 20.5 \\
\hline
\end{tabular}

HIV Human immunodeficiency virus, OCP Oral contraceptive pills, STI Sexually transmitted infection

higher than from that of ECA among HIV- women. Relatively concordant results on the prevalence of ECA among HIV-infected women were reported from Tanzania (17\%) [31] and Thailand (15.4\%) consisting of ASCUS $2.8 \%$, LSIL $8.5 \%$, and HSIL $3.5 \%$ [32]. On the other hand, lower prevalence of ECA (2.8\%) was reported among Turkish women of which $2.2 \%$ was ASCUS, $0.5 \%$ LSIL, $0.1 \%$ HSIL and $0.0 \%$ SCC [33]. In different regions of Nigeria, Pap smear screening have shown a lower prevalence of HPV induced cervical ECA $(7.6-13.2 \%)$ [34, 35]. Similarly, based on Bethesda

Table 4 The prevalence of epithelial cell abnormality among women attending cervical cancer screening unit at Debre Markos referral hospital

\begin{tabular}{|c|c|c|c|c|c|}
\hline \multicolumn{2}{|c|}{ Cervical cytology result } & \multicolumn{2}{|l|}{ HIV status } & \multicolumn{2}{|c|}{ Total tested } \\
\hline & & Positive & Negative & $n$ & $\%$ \\
\hline$\overline{N I L}$ & & $162(82.2 \%)$ & $174(89.7 \%)$ & 336 & 85.9 \\
\hline ECA & & $35(17.8 \%)$ & $20(10.3 \%)$ & 55 & 14.1 \\
\hline \multirow[t]{4}{*}{ Types of ECA } & ASCUS & $11(5.6 \%)$ & $9(4.6 \%)$ & 20 & 5.1 \\
\hline & LSIL & $12(6.1 \%)$ & $3(1.5 \%)$ & 15 & 3.8 \\
\hline & HSIL & 10(5.1\%) & $6(3.1 \%)$ & 16 & 4.1 \\
\hline & SCC & $2(1.0 \%)$ & $2(1.0 \%)$ & 4 & 1.1 \\
\hline
\end{tabular}

NIL Negative for intraepithelial lesion, ECA Cervical epithelial cell abnormality, ASCUS atypical squamous cell undetermined significance, LSIL Low grade squamous intraepithelial lesion, HSIL High grade squamous intraepithelial lesion, SCC squamous cell carcinoma, HIV Human immunodeficiency virus
System ECA classification, the study conducted in Nigeria among young females indicated that the prevalence of ASCUS was $7 \%$, LSIL $12.2 \%$, HSIL $7.7 \%$ and SCC $0.7 \%$ [35]. Another study among Italian women also reported $2.8 \%$ ASCUS, $6.2 \%$ LSIL and $1.7 \%$ HSIL cervical cytological abnormalities [36]. In contrast, higher prevalence of HPV induced cervical ECA was observed in South Africa in which 41.7, 70.2 and $83 \%$ were ASCUS, LSILS and HSIL, respectively [21]. In

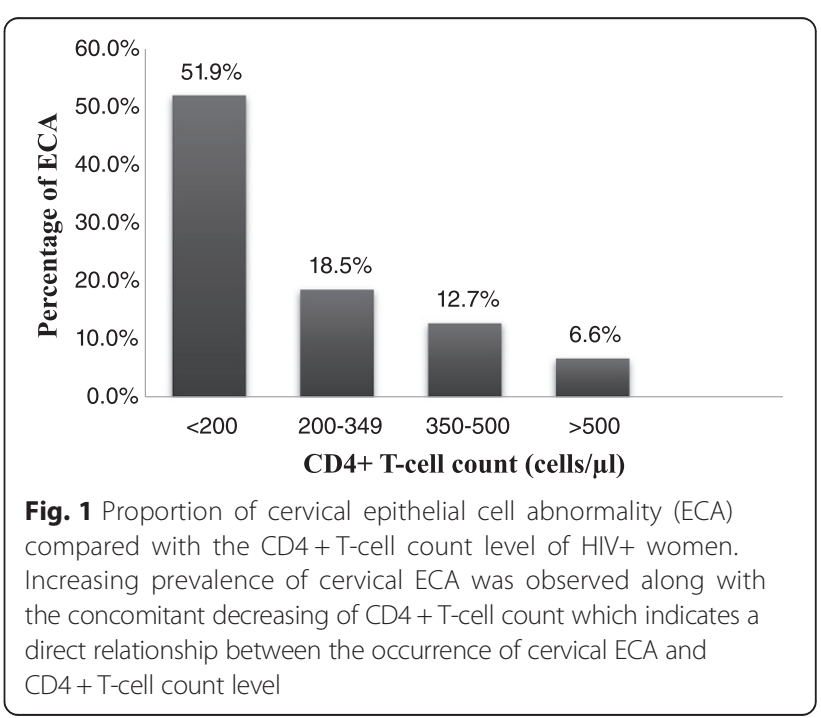


Table 5 Bivariate and multivariate analysis of risk factors for cervical ECA among women attending cervical cancer screening unit at Debre Markos referral hospital

\begin{tabular}{|c|c|c|c|c|c|c|c|}
\hline \multirow[t]{3}{*}{ Variables } & & \multicolumn{2}{|c|}{ Cervical ECA } & \multirow[t]{3}{*}{ COR (95 \% Cl) } & \multirow[t]{3}{*}{$P$} & \multirow[t]{3}{*}{ AOR $(95 \% \mathrm{Cl})$} & \multirow[t]{3}{*}{ P } \\
\hline & & Yes & No & & & & \\
\hline & & No (\%) & No (\%) & & & & \\
\hline \multirow[t]{3}{*}{ Age (in year) } & $<30$ & $11(7.4)$ & 138(92.6) & 1 & & 1 & \\
\hline & $30-45$ & $33(16.7)$ & 165(83.3) & $2.5(1.22,5.11)$ & 0.012 & $0.8(0.30,2.09)$ & 0.648 \\
\hline & $>45$ & $11(25.0)$ & $33(75.0)$ & $4.2(1.67,10.47)$ & 0.002 & $0.6(0.18,2.25)$ & 0.493 \\
\hline \multirow[t]{4}{*}{ Marital status } & Married & $21(9.1)$ & 209(90.9) & 1 & & 1 & \\
\hline & Single & $1(3.2)$ & 30(96.8) & $0.3(0.04,2.55)$ & 0.290 & $1.2(0.11,12.43)$ & 0.869 \\
\hline & Divorced & $15(21.1)$ & $56(78.9)$ & $2.7(1.29,5.50)$ & 0.008 & $3.2(1.19,8.77)$ & 0.021 \\
\hline & Widowed & 18(30.5) & $41(69.5)$ & $4.4(2.14,8.91)$ & 0.000 & $3.0(1.12,8.09)$ & 0.029 \\
\hline \multirow[t]{2}{*}{ Education } & NFE & $35(19.8)$ & 142(80.2) & $2.6(0.87,7.69)$ & 0.087 & $2.2(0.69,6.67)$ & 0.181 \\
\hline & Primary & $16(9.5)$ & 152(90.5) & 1 & & 1 & \\
\hline \multirow[t]{5}{*}{ Occupation } & Employed & $6(9.2)$ & $59(90.8)$ & 1 & & 1 & \\
\hline & HW & 28(18.3) & 165(81.7) & $1.8(0.29,10.76)$ & 0.275 & $0.4(0.10,1.88)$ & 0.536 \\
\hline & $\mathrm{DL}$ & $10(16.7)$ & $50(83.3)$ & $2.9(0.64,12.86)$ & 0.167 & $0.3(0.05,1.86)$ & 0.205 \\
\hline & CSW & $4(18.2)$ & 18(81.8) & $1.6(0.27,9.93)$ & 0.004 & $0.1(0.01,0.95)$ & 0.046 \\
\hline & Others & $7(14.6)$ & $41(85.4)$ & $2.6(0.80,8.25)$ & 0.081 & $0.8(0.17,1.16)$ & 0.112 \\
\hline \multirow[t]{3}{*}{ Age of $1^{\text {st }}$ sex (in year) } & $<15$ & $42(23.5)$ & 137(76.5) & $7.7(2.68,22.28)$ & $<0.001$ & $5.2(1.49,17.95)$ & 0.009 \\
\hline & 15-18 & $9(8.4)$ & $98(91.6)$ & $2.3(069,7.77)$ & 0.173 & $2.4(0.61,9.49)$ & 0.208 \\
\hline & $>18$ & $4(3.8)$ & $101(96.2)$ & 1 & & 1 & \\
\hline \multirow[t]{2}{*}{ No. of sexual partner } & $1-2$ & $21(8.3)$ & 233(91.7) & 1 & & 1 & \\
\hline & $3-4$ & $34(24.8)$ & 103(75.2) & $3.6(1.84,6.96)$ & $<0.001$ & $3.2(1.00,10.03)$ & 0.048 \\
\hline \multirow[t]{2}{*}{ History of STI } & Yes & 21(20.6) & $81(79.4)$ & $1.9(1.06,3.53)$ & 0.029 & $1.5(0.67,3.42)$ & 0.314 \\
\hline & No & $34(11.8)$ & 255(88.2) & 1 & & 1 & \\
\hline \multirow[t]{3}{*}{ OCP user (in year) } & $<5$ & $7(9.1)$ & $70(90.9)$ & 1 & & 1 & \\
\hline & $\geq 5$ & $16(76.2)$ & $5(23.8)$ & $30.0(7.6,118.37)$ & $<0.001$ & $11.9(2.11,16.69)$ & 0.020 \\
\hline & No & 14(11.3) & $110(88.7)$ & 1 & & 1 & \\
\hline \multirow[t]{3}{*}{ Parity } & $\leq 2$ & $13(5.6)$ & 219(94.4) & 1 & & 1 & \\
\hline & $3-4$ & $6(10.7)$ & $50(89.3)$ & $3.2(1.36,7.30)$ & 0.007 & $1.7(0.53,5.44)$ & 0.362 \\
\hline & $>4$ & $36(35.0)$ & $67(65.0)$ & $7.9(3.67,16.92)$ & $<0.001$ & $10.9(4.16,16.75)$ & $<0.001$ \\
\hline \multirow[t]{2}{*}{ HIV status } & Negative & 20(10.3) & 174(89.7) & 1 & & 1 & \\
\hline & Positive & $35(17.8)$ & 162(82.2) & $1.9(1.04,3.38)$ & 0.036 & $1.4(0.62,3.16)$ & 0.410 \\
\hline \multirow[t]{4}{*}{ CD4 + T-cell count (cells/ $\mu$ l) } & $<200$ & 14(51.9) & 13(48.1) & $15.3(4.33,54.31)$ & $<0.001$ & $14.1(6.69,16.4)$ & $<0.001$ \\
\hline & 200-349 & 10(18.5) & $44(81.5)$ & $3.2(0.95,11.01)$ & 0.060 & $9.6(1.79,11.54)$ & 0.008 \\
\hline & $350-500$ & $7(12.7)$ & $48(87.3)$ & $2.1(0.57,7.52)$ & 0.265 & $5.8(0.98,31.62)$ & 0.052 \\
\hline & $>500$ & $4(6.6)$ & $57(93.4)$ & 1 & & 1 & \\
\hline
\end{tabular}

HIV Human immunodeficiency virus, COR crude odds ratio, AOR adjusted odds ratio, $C I$ confidence interval, $P$ p- value, OCP Oral contraceptive pills, STI Sexually transmitted infection, NFE No formal education, CSW Commercial sex worker, HW House wife, DL Daily laborer

another study carried among Turkish women, higher prevalence of ECA (54.8\%) was observed. The prevalence of ASCUS was $36.7 \%$, LSIL $16.8 \%$, HSIL $1.3 \%$ [37]. The discrepancy in the prevalence of ECA between these studies may be due to differences in the study population. Higher prevalence of ECA observed from our finding and the report from South Africa may be due to the inclusion of high number of
HIV-infected women. HIV is reported as one of the independent risk factor for development of cervical ECA and cervical cancer.

Women in the age groups of 30 years and older were at greater risk of developing ECA in the present study. There are also some other study findings which indicate that older age women had greater risk for the development of ECA. Cervical cancer mortality, 
usually occurring among unscreened women, increases with age, with the maximum mortality rate reported for white women between age 45 years and 70 years, and for black women in their 70s [38, 39]. Mortality among women with negative Pap smear screening is low at all ages. The prevalence of SCC and ASCUS were 36.4 and $81.8 \%$ respectively among women $<30$ years of age. ASCUS was found to be highest in the youngest age group women in this study.

The study participants were stratified by their HIV status and data of 197 (50.4 \%) HIV+ and 194 (49.6\%) HIV- women were analyzed. We found higher prevalence of cervical ECA (17.8 \%) among HIV+ women as compared to HIV- women (10.3\%). This finding was very similar to the study finding reported from Brazil where ECA was more common in the HIV+ group (12.1\%) compared to the HIV-group (5.4\%) [40]. In a study finding reported from India, all cervical ECA (26.35 \%) were found among HIV+ women [41]. HIV infection is one of the major risk factor that contributes for the growth of cervical ECA. HIV leads to an increased risk of CIN and cervical cancer [40]. Up to $20 \%$ of HIV coinfected patients develop HPV-induced premalignant lesions of the uterine cervix within three years of HIV diagnosis [42]. Progression of an untreated HPV-induced dysplastic lesion can lead to invasive cervical cancer, an AIDS defining illness [43].

Moreover, the prevalence of ECA in this study was significantly higher among HIV+ women with lower CD $4+$ T-cell counts of $<350$ cells $/ \mu l$. Statistically significant downward trends of the prevalence of ECA along the increment of CD4+ T-cell counts in HIV+ women was observed in the present study. Similarly, higher prevalence of ECA among HIV+ women with lower $\mathrm{CD}+\mathrm{T}$-cell counts of $<200$ cells/ $\mu \mathrm{l}$ was reported $[40,44]$. There are study reports that documented the higher risk of cervical ECA when CD4+ T-cell counts fall below $<200$ cells $/ \mu \mathrm{l} \quad[25,28]$. Decreased CD4+ T-cells count and increased HIVRNA levels are risk factors for CIN. In addition, it has also been shown that with decreasing numbers of $\mathrm{CD} 4+\mathrm{T}$-cells, there is an increase in both frequency and severity of cervical dysplasia in HIV-infected women [36, 45]. Significant correlation was reported between low levels of CD4+ T-cells, high HIV-viral load and risk of CIN [46]. A Brazilian study demonstrated that immunosuppressed women had a higher risk of lesion recurrence as compared to women with a CD4+ T-cells count $>200$ cells/ $\mu$ l [47].

In our study widowed (30.5\%) and divorced $(21.1 \%)$ women were significantly at higher risk for the development of ECA when compared to married $(9.1 \%)$ women. This difference might be due to divorced and widowed women may have multiple sexual partners when compared to married women. This finding is supported by the report from Ghana in which higher prevalence of ECA (21.3\%) was observed in polygamous women when compared to monogamous women (13.9 \%) [48]. In this study, women with a history of STI were 1.5 times more likely to develop cervical ECA than women with no history of STI. Previous reports also demonstrated that genital infections were risk factors for the acquisition of HPV infection and the progression of cervical cancer $[35,43,44]$.

We identified earlier initiation of first sexual contact $(<15$ years) as a significant risk factor for the development of ECA. Women with previous history of multiple life time sexual partners (more than two) were also at high risk for developing ECA which is supported by the study reported from Tanzania (44). Another most important finding of this study was that women with higher parity (greater than four) were 10.9 times more likely to develop ECA as compared to women with parity less than three. OCP users for more than 5 years had higher risk for the presence of ECA than their counterparts. Similar study supported that the prevalence of cervical cancer associated death in Ghana [48] among OCP users was higher.

\section{Limitation}

The limitation of this study is that the number of study participants is relatively small for an epidemiological study; the results may only be applied to Northwest Ethiopia. Most of the study subjects were patients with gynecological problems which may not represent the general population. The result of this study also may not represent the hospital catchment population for most of women attending the cervical screening center are HIV+. The short duration of the study did not allow the adequate follow up of the disease progression. Moreover, the study didn't further assess the etiology of the ECA.

\section{Conclusions}

Women infected with HIV had a greater risk of developing cervical ECA than HIV- women. There was a downward trend of the prevalence of ECA along the increment of CD4+ T-cell counts among HIV-infected women. Lower CD4+ T-cell counts of below 350 cells $/ \mu \mathrm{l}$, earlier initiation of first sexual contact (at the age of $<15$ years), parity greater than four, being widowed and divorced, multiple sexual partnership (more than three partners) and long term OCP use were significant predictors of increased risk of cervical ECA. Hence, cytological screening program should be targeting specifically HIV+ women. Awareness creation on risk factors as multiple sexual partnership and sexual initiation at earlier age should be provided. 


\section{Abbreviations}

ASCUS: Atypical squamous cell undetermined significance; CIN: Cervical intraepithelial neoplasia; ECA: Cervical epithelial cell abnormality; HIV: Human immunodeficiency virus; HR: High risk; HPV: Human papillomavirus; HSIL: High grade squamous intraepithelial lesion; LR: Low risk; LSIL: Low grade squamous intraepithelial lesion; NIL: Negative for intraepithelial lesion; OCP: Oral contraceptive pills; SCC: Squamous cell carcinoma; SIL: Squamous intraepithelial lesion; STI: Sexually transmitted infection.

\section{Competing interests}

The authors declare that they have no competing interests.

\section{Authors' contributions}

MG proposed the initial idea for the study. MG, BG and AA contributed to the study design. MG and AS collected all the data. All authors analyzed and interpreted the data. MG drafted the manuscript. All authors contributed to the writing of the manuscript. AA prepared the manuscript for publication. All authors read and approved the final manuscript.

\section{Authors' information}

MG: MSc in medical microbiology; BG: PhD, associate professor of medical microbiology; AA: MSc, lecturer in clinical microbiology; AS: MD, gynecologist, EM: Professor, MD, MPH, Pathology, Director of Global Health Program.

\section{Availability of data and materials}

Not applicable

\section{Acknowledgements}

We would like to thank Debre Markos hospital for all the help and support provided during data collection, cytopathological examination and other laboratory investigation. We also thank the Amhara Regional Health Bureau for financial support. We gratefully acknowledge all study participants for their participation in the study. Lastly we would like to acknowledge University of Gondar department of pathology for examination of Pap smear slides.

\section{Author details}

1Debre Markos Referral Hospital, Debre Markos, Ethiopia. ²Department of Medical Microbiology, School of Biomedical and Laboratory Sciences, College of Medicine and Health Sciences, University of Gondar, Gondar, Ethiopia. ${ }^{3}$ Department of Basic Sciences, College of Osteopathic Medicine, Touro University, Vallejo, CA, USA.

Received: 21 August 2014 Accepted: 8 September 2015

\section{Published online: 23 September 2015}

\section{References}

1. Tornesello ML, Buonaguro L, Giorgi-Rossi P, Buonaguro FM. Viral and cellular biomarkers in the diagnosis of cervical intraepithelial neoplasia and cancer. Biomed Res Int. 2013;2013:519619.

2. Saslow D, Castle PE, Cox JT, Davey DD, Einstein MH, Ferris DG, et al. American Cancer Society Guideline for human papillomavirus (HPV) vaccine use to prevent cervical cancer and its precursors. CA Cancer J Clin. 2007:57:7-28.

3. Trottier H, Franco EL. The epidemiology of genital human papillomavirus infection. Vaccine. 2006;24 Suppl 1:S1-15.

4. Pande $\mathrm{S}$, Jain N, Prusty BK, Bhambhani S, Gupta S, Sharma R, et al. Human papillomavirus type 16 variant analysis of E6, E7, and L1 genes and long control region in biopsy samples from cervical cancer patients in north India. J Clin Microbiol. 2008:46:1060-6.

5. Gagnon S, Hankins C, Tremblay C, Forest P, Pourreaux K, Coutlée F, et al. Viral polymorphism in human papillomavirus types 33and 35 and persistent and transient infection in the genital tract of women. J Infect Dis. 2004;190:1575-85.

6. Ault KA. Epidemiology and natural history of human papillomavirus infections in the female genital tract [Review]. Infect Dis Obstet Gynecol. 2006;Suppl:40470.

7. Bosch F, Sanjose S. Chapter 1: human papillomavirus and cervical cancer-burden and assessment of causality. J Natl Cancer Inst Monogr. 2003;3-13.
8. Gillison ML, Broutian T, Pickard RK, Tong ZY, Xiao W, Kahle L, et al. Prevalence of oral HPV infection in the United States, 2009-2010. JAMA. 2012;307:693-703.

9. World Health Organization (WHO). Human Papillomavirus and Related Cancers. Summary Report Update. 2010. Available at: http://screening.iarc.fr/doc/ Human\%20Papillomavirus\%20and\%20Related\%20Cancers.pdf.. Accessed on Dec 23, 2013.

10. Franco EL, Villa LL, Sobrinho JP, Prado JM, Rousseau MC, Désy M, et al. Epidemiology of acquisition and clearance of cervical human papillomavirus infection in women from a high-risk area for cervical cancer. J Infect Dis. 1999:180:1415-23.

11. Kerr DJ, Fiander AN. Towards Prevention of Cervical Cancer in Africa. 2009. Available at: www.afrox.org. Accessed on Dec 15, 2013.

12. Hariri $S$, Unger ER, Sternberg M, Dunne EF, Swan D, Patel S, et al. Prevalence of genital human papillomavirus among females in the United States, the National Health and Nutrition Examination Survey, 2003-2006. J Infect Dis. 2011;204:566-73.

13. Abdull Gaffar B, Kamal MO, Hasoub A. The prevalence of abnormal cervical cytology in women with infertility. Diagn Cytopathol. 2010;38:791-4.

14. Hailu A, Mariam DH. Patient side cost and its predictors for cervical cancer in Ethiopia: a cross sectional hospital based study. BMC Cancer. 2013;13:69.

15. Cutts FT, Franceschi S, Goldie S, Castellsague X, de Sanjose S, Garnett G, et al. Human papillomavirus and HPV vaccines: a review. Bull. 2007; 85(9):71926.

16. Luyten A, Buttmann-Schweiger N, Luyten K, Mauritz C, Reinecke-Lüthge A, Pietralla $\mathrm{M}$, et al. Early detection of CIN3 and cervical cancer during longterm follow-up using HPV/Pap smear co-testing and risk-adapted follow-up in locally organized screening programs. Int J Cancer. 2014;135:1408-16.

17. Solomon D, Davey D, Kurman R, Moriarty A, O'Connor D, Prey M, et al. Bethesda 2001 Workshop: The 2001 Bethesda System: terminology for reporting results of cervical cytology. JAMA. 2002;287:2114-9.

18. Mayrand MH, Duarte-Franco E, Rodrigues I, Walter SD, Hanley J, Ferenczy A, et al. Human papillomavirus DNA versus Papanicolaou screening tests for cervical cancer. N Engl J Med. 2007;357:1579-88.

19. Richter K, Becker P, Horton A, Dreyer G. Age-specific prevalence of cervical human papillomavirus infection and cytological abnormalities in women in Gauteng Province, South Africa. S Afr Med J. 2013;103:313-7.

20. Allan B, Marais DJ, Hoffman M, Shapiro S, Williamson AL. Cervical human papillomavirus (HPV) infection in South African women: implications for HPV screening and vaccine strategies. J Clin Microbiol. 2008;46:740-2.

21. Firnhaber C, Van Le H, Pettifor A, Schulze D, Michelow P, Sanne IM, et al. Association between cervical dysplasia and human papillomavirus in HIV seropositive women from Johannesburg South Africa. Cancer Causes Control. 2010;21:433-43.

22. Daniel T, Juana S. Human Papillomavirus infection and cervical cancer: pathogenesis and epidemiology. 2007. Available at: http://www.formatex.org/ microbio/pdf/pages680-688.pdf. Accessed on Dec 8, 2013.

23. Kravchenko J, Akushevich I, Sudenga SL, Wilson CM, Levitan EB. ShresthaS: Transitional probability-based model for HPV clearance in HIV-1positiveadolescent females. PLoS One. 2012;7:e30736.

24. Abraham AG, D'Souza G, Jing Y, Gange SJ, Sterling TR, Silverberg MJ, et al. Invasive cervical cancer risk among HIV-infected women: a North American multi-cohort collaboration prospective study. J Acquir Immune Defic Syndr. 2013;62:405-13.

25. Terry R. Management of patients with atypical squamous cells of undetermined significance (ASCUS) on Papanicolaou smears. J Am Osteopath Assoc. 1996:96(8):465-8.

26. Elfström KM, Herweijer E, Sundström K, Arnheim-Dahlström L. Current cervical cancer prevention strategies including cervical screening and prophylactic human papillomavirus vaccination: a review. Curr Opin Onco. 2014;26:120-9.

27. Palefsky J. HPV infection and HPV-associated neoplasia in immunocompromised women. Int J Gynaecol Obstet. 2006;94:S56-64.

28. Anastos K, Hoover DR, Burk RD, Cajigas A, Shi Q, Singh DK, et al. Risk factors for cervical precancer and cancer in HIV-infected, HPV-positive Rwandan women. PLoS One. 2010;5:e13525.

29. Combating-Cervical-Cancer-in-Ethiopia.pdf. 2010. http://www.pathfinder.org/ publications-tools/pdfs/Combating-Cervical-Cancer-in-Ethiopia.pdf. Accessed on Feb 15, 2015.

30. Srivastava S, Gupta S, Roy JK. High prevalence of oncogenic HPV-16 in cervical smears of asymptomatic women of eastern Uttar Pradesh, India: a population-based study. J Biosci. 2012;37:63-72. 
31. Obure J, Olola O, Swai B, Mlay P, Masenga G, Walmer D. Prevalence and severity of cervical squamous intraepithelial lesion in a tertiary hospital in northern Tanzania. Tanzan J Health Res. 2009;11:163-9.

32. Chalermchockcharoenkit A, Chayachinda C, Thamkhantho M, Komoltri C. Prevalence and cumulative incidence of abnormal cervical cytology among HIV-infected Thai women: a 5.5-year retrospective cohort study. BMC Infect Dis. 2011;11:8.

33. Açikgöz A, Ergör G. Cervical cancer risk levels in Turkey and compliance to the national cervical cancer screening standard. Asian Pac J Cancer Prev. 2011;12:923-7.

34. Patrıcia A, Marco T, Suelene B. Cervical Cytopathology in a Population of HIV-Positive and HIV-Negative Women. J Trop Med. 2012;869758.

35. Durowade KA, Osagbemi GK, Salaudeen AG, Musa OI, Akande TM Babatunde OA, et al. Prevalence and risk factors of cervical cancer among women in an urban community of Kwara State, north central Nigeria. J Prev Med Hyg. 2012;53:213-9.

36. Meloni A, Pilia R, Campagna M, Usai A, Masia G, Caredda V, et al. Prevalence and molecular epidemiology of human papillomavirus infection in Italian women with cervical cytological abnormalities. J Public Health Res. 2014;3:157.

37. Atilgan R, Celik A, Boztosun A, Ilter E, Yalta T, Ozercan R. Evaluation of cervical cytological abnormalities in Turkish population. Indian J Patho Microbiol. 2012;55:52-5.

38. Saslow D, Runowicz CD, Solomon D, Moscicki AB, Smith RA, Eyre HJ, et al. American Cancer Society guideline for the early detection of cervical neoplasia and cancer. CA Cancer J Clin. 2002:52:342-62.

39. National Institutes of Health Consensus Development Conference Statement: cervical cancer, April 1-3. National Institutes of Health Consensus Development Panel. J Natl Cancer Inst Monogr. 1996;1996:vii-xix.

40. Heard I, Tassie JM, Schmitz V, Mandelbrot L, Kazatchkine MD, Orth G. Increased risk of cervical disease among human immunodeficiency virus-infected women with severe immunosuppression and high human papillomavirus load(1). Obstet Gynecol. 2000;96:403-9.

41. Lima MA, Tafuri A, Araújo AC, Lima LM, Melo VH. Cervical intraepithelial neoplasia recurrence after colonization in HIV-positive and HIV-negative women. IntJ Gynecol Obstet. 2009;104:100-04.

42. Jamieson DJ, Duerr A, Burk R, Klein RS, Paramsothy P, Schuman $P$, et al. Characterization of genital human papillomavirus infection in women who have or who are at risk of having HIV infection. Am J Obstet Gynecol. 2002;186:21-7.

43. Hatuvedi AK, Madeleine MM, Biggar RJ, Engels EA. Risk of human papillomavirus -associated cancers among persons with AIDS. J Natl Cancer Inst. 2009;101:1120-30.

44. Kafuruki L, Rambau PF, Massinde A, Masalu N. Prevalence and predictors of cervical intraepithelial neoplasia among HIV infected women at Bugando Medical Centre, Mwanza-Tanzania. Infect Agent Cancer. 2013:8(1):45.

45. Harris TG, Burk RD, Palefsky JM, Massad LS, Bang JY, Anastos K, et al. Incidence of cervical squamous intraepithelial lesions associated with HIV sero-status, CD4 cell counts, and human papillomavirus test results. JAMA. 2005;293:1471-6.

46. Hawes SE, Critchlow CW, Sow PS, Touré P, N'Doye I, Diop A, et al. Incident high-grade squamous intraepithelial lesions in Senegales women with and without human immunodeficiency virus type 1 (HIV-1) and HIV-2. J Natl Cancer Inst. 2006:98:100-9.

47. Russomano F, Paz BR, Camargo MJ, Grinstejn BG, Friedman RK, Tristao MA et al. Recurrence of cervical intraepithelial neoplasia in human immunodeficiency virus-infected women treated by means of electrosurgical excision of the transformation zone (LLETZ) in Rio de Janeiro, Brazil. Sao Paulo Med J. 2013;131(6):405-10.

48. Domfeh A, Wiredu E, Adjei A, Ayeh-Kumi P, Adiku T, Tettey Y, et al. Cervical human papillomavirus infection in Accra, Ghana. Ghana Med J. 2008:42:71-8.

\section{Submit your next manuscript to BioMed Central and take full advantage of:}

- Convenient online submission

- Thorough peer review

- No space constraints or color figure charges

- Immediate publication on acceptance

- Inclusion in PubMed, CAS, Scopus and Google Scholar

- Research which is freely available for redistribution

Submit your manuscript at www.biomedcentral.com/submit 